Learning, knowledge and authority on site: a case study of safety practice.

John Rooke \& Leslie Clark,

Published as:

Rooke, J. \& Clark, L. (2005) 'Learning, knowledge and authority on site: a case study of safety practice’, Building Research and Information, 33(6):561-570. 


\section{Learning, knowledge and authority on site: a case study of safety practice.}

Abstract: The ethnographic research reported here reveals patterns of authority and learning on an experimental construction site that are significant for the promotion of a safety culture. This research seeks to display the methods of understanding used by site personnel to constitute the construction site as a local work site. Findings confirm insights from previous studies and reveal, in addition: the trial and error nature of much site learning; alternative bodies of knowledge underpinning competing authority structures; the authority of elite manual workers; the complexity of informal authority; the ambiguity and limitations of formal authority. The experiential knowledge which is valued by site personnel forms a basis for the recognition of authority on site which can conflict with that of construction professionals. These forms of authority and experiential knowledge can inhibit the dissemination of good safety practice: initiatives will meet significant resistance if they contradict the experiential knowledge of site operatives; initiatives that do not make use of this experiential knowledge may fail to fully address hazards; methods of learning on site, particularly in the development of innovative practice are inherently hazardous.

Keywords: Ethnography, Unique Adequacy Requirement, Health and Safety, Site Management, Knowledge, Authority, Organisation, Organisational Culture. 


\section{Introduction}

The incidence rate for death and serious injury on UK construction sites remains significantly higher than that for UK industry as a whole and previous research has highlighted a need for the promotion of organisational learning in the field of health and safety (Whittington, Livingston \& Lucas 1992). Ethnographic research from construction sites in the UK and elsewhere has identified some important findings that bear on the possibility of achieving this goal, including: the existence of formally unrecognised skills in the concreting industry (Seymour \& Hill 1995); the importance of a community of practice in the dissemination of knowledge (Gherardi \& Nicolini 2002); the existence of competing bodies of knowledge on construction sites (Rooke \& Seymour 2002); the existence of competing authority structures (Appelbaum 1982); the central importance of the craft based site manager in site administration (Seymour \& Hill 1995).

The ethnographic research reported here offers further insights into patterns of authority and learning on site. It was conducted according to the unique adequacy (henceforth UA) requirement of methods, in that it seeks to display a competence in the methods of understanding used by site personnel to constitute the construction site as a local work site (Garfinkel \& Wieder 1992, Garfinkel 2002). Participant observation, a method of ethnographic enquiry which involves the researcher taking an active part in the setting under study, was used in order to research the erection of a seven story concrete frame. Knowledge of the setting 
was thus acquired through instruction from other members of that setting and through direct experience. Findings confirm the insights from previous studies listed above, while contributing new insights pertaining to knowledge and learning processes on site and the way these underpin prevailing authority relations.

\section{Safety, ethnography and learning in the UK construction industry}

Statistical data show the UK construction industry to suffer from a disproportionate incidence of deaths and serious injuries as compared to UK industry as a whole. In 2002, the rate of fatal and major injuries was 244 per 100,000 , with a fatality rate of 4.2 per 100,000 , as compared with 0.88 for UK industry as a whole (Myers 2003). Despite recent improvements, the Health and Safety Executive reports that “convincing evidence” of “ an inexorable downward trend” (ibid. p2) is still lacking and that the industry "remains one of the most dangerous in Britain” (ibid. p5).

The reasons for this have been well rehearsed. Harvey \& Ashworth observe that the industry is "labour intensive and heavily craft based” (1997, p246). It is highly vulnerable to economic cycles and has been subject to successive job losses and cuts in training expenditure. For instance, in the early 1980's expenditure in training was cut by $30 \%$ and in the early 1990s a further $£ 706 \mathrm{~m}$ 
was cut from training budgets. Harvey \& Ashworth (1997) assert that major contractors rarely train. During this period the structure of the industry also changed. An increasing emphasis on sub-contracting has led, on the one hand, to an increased number of small firms and, on the other, a high rate of self employment. Harvey \& Ashworth put the figure for self employment as high as $40 \%$ in the early 1990 's, while Clarke \& Wall (1998) put it at $60 \%$ by the latter half of the decade, though as Morton (2002) notes, establishing whether or not a worker is truly self employed is not a straightforward matter. Self employment has been growing since at least the 1960's. Union membership is low: $30 \%$ in the early 1980 's, falling to $20 \%$ by the end of the decade (ibid).

It is against this background that Whittington, Livingston and Lucas (1992) called for the development of organizational learning in matters of construction site safety. Clearly, the trends discussed above are likely to have a disruptive effect on the learning ability of construction organisations and a consequent negative impact on efforts to improve safety performance. In addition, as will be argued below, because of the way in which learning takes place on site, it is difficult to achieve this end through the means of conventional record keeping. Knowledge is held by individuals and may be passed from individual to individual, but is unlikely to be adequately recorded. On the other hand, as Clarke \& Wall (1998) point out, despite increasing casualisation and chronic skills shortages, there exists a reservoir of unrecognised skills often in the possession of so called 'labourers'. They single out concreting as a particularly problematic area with regards to defining skills. In this paper we will argue, drawing on participant observation 
research, that the existence of this hidden skill base and the authority relations it engenders, have important consequences for the development of safety practice.

Ethnographies of the construction industry are sparse. However, there exists a handful of excellent studies that go a long way towards providing a comprehensive description. An early US study by Appelbaum (1982) highlights a disjuncture between the traditional mode of construction management and the, then newly introduced, bureaucratic mode. He finds that the former, administered through face to face contact between site personnel and based on the competence of skilled craftsmen actually controls site activity; while the latter, paper oriented and shy of making production decisions, has little or no influence. He observes that:

"we have virtually two separate organizations: one for the management function and one for getting the work done. The two organizations do not coordinate their work, and they are characterized by different goals and viewpoints.” p229

Thirteen years later, Seymour and Hill (1995) explore the traditional side of this dichotomy in the context of a similar situation in the UK industry. They find that the site foreman, with a craft based competence is central to the site administration. Foremen build their own teams of operatives, which tend to stay together from job to job. Thus, they consciously create and maintain around themselves an informal organization in which knowledge and skill are not simply 
the possession of individuals, but a resource for the whole team.

More recently, drawing on several years of research on various projects, Rooke \& Seymour (2002) have posited the existence of two competing bodies of knowledge on construction sites, based respectively in experiential and classroom taught modes of learning. Differential judgements arising from these alternate knowledge bases can provide for actions on site which are at once controversial, yet fully justified in the eyes of those who take them. Thus, for example, the removal of a quantity of reinforcement from a slab on the grounds that it was excessive was seen by the contractor as corrective measure to the consultant's over-design, whereas engineers later commenting on this action characterised it as irresponsible and dishonest.

Further insight into the nature of the shared knowledge of the site is provided by Gherardi \& Nicolini (2002) who report on an Italian site and focus specifically on safety issues, characterising the knowledge base as a 'community of practice'. Their findings emphasise the interdependence of knowledge and practice and the social nature of knowledge and the learning process. "Safety," they observe, “consists of a mental habit applied in everyday action, and it is an aspect of practice that is not taught explicitly, but which must be practised” (p216). New members to a culture of practice become knowledgeable in the course of a social process which involves seeing how others in the community behave, asking appropriate questions and attempting to perform appropriately. This is "an active, reciprocal endeavour” (p216), the resulting knowledge taking the form of “a 
capacity to perform competently in a specific socio-cultural activity” (p217). Thus, organization, knowledge and identity are inseparable, constituting a "sense of what is safe $[. .$.$] novices need to learn how to feel [. .$.$] experience and interact$ with their new physical and social environment” (p217).

Gherardi \& Nicolini draw on contemporary learning theory for their notion of a community of practice. Developed in the work of Lave and Wenger (1991) which itself draws on ethnographic studies for its inspiration, the concept draws attention to the situated and social nature of knowledge and learning. Blackler (1995) synthesises Lave's (1993) rejection of the conception of knowledge as objective, eternal and universal with Engeström's (1987) suggestion that 'social activity system' constitutes a more appropriate unit of analysis than either 'individual' or 'organization'. To these he emphasises a third consideration, already present in Lave \& Wenger's earlier study, that knowledge can be contested in the context of unequal power relationships. Despite this early emphasis, Contu and Willmott (2003) express concern that the significance of power relations continues to be overlooked in situated learning studies, a concern that is possibly also implicit in Engeström's (2004) suggestion that a greater focus on structural issues might now be appropriate. For the former, this deficiency is to be remedied by a focus on historical antecedents. In a detailed review of Lave and Wenger, as well as Orr $(1990,1996)$ they show how contested relations are systematically written out of the literature. 


\section{Methodological considerations}

A consistent picture emerges from the ethnographic studies reviewed above. Many of the insights recorded are both confirmed and extended by our own findings reported below. Yet ethnographic findings have had little currency among construction management academics and practitioners. There has been little attempt to explain this situation, but in response to a similar condition of research in human geography, Herbert (2000) has suggested that there are three generic objections to ethnographic research, respectively: unease with the emphasis on subjective interpretation in the assembly of data; doubts as to the generalizability of ethnographic findings; concern over the representational practices involved in ethnographic reporting.

(i) The necessity of interpretation and the unique adequacy requirement of methods

Thus, one strand of criticism of ethnography focuses on the supposedly unusual prominence of interpretive methods in ethnography, though as Herbert points out “interpretive practices are central to all science” (ibid. p558). Ethnographic studies of science have amply demonstrated the interpretive practices that take place in scientific laboratories. Garfinkel, Lynch and Livingston (1981) for example, produce transcript of audio tapes recording the discovery in real time of 
an optical pulsar. It is clear from this record that the discovery involves a collective process of interpretation in which the scientists present must decide whether or not the visual readings they take from their instruments truly represent a real optical pulsar (as opposed to, say, noise, or instrument malfunction).

Notwithstanding these and similar observations, Herbert points out the importance for any science of demonstrating that a particular set of interpretations are better than others. Rooke, Seymour \& Fellows (2004) suggest the unique adequacy requirement of methods (Garfinkel \& Wieder 1992, Garfinkel 2002) as a means of achieving this for ethnographic studies. The report of findings given below is designed to meet the criteria embodied in this requirement.

As Rooke et al state:

"These criteria are founded on the principle that the activities and procedures of persons in a setting can best be accounted for in terms of the understandings that those persons have of that setting. Thus, the task of the ethnographer is to render a clear description of those understandings, rather than offer an explanatory theory.” (ibid. p656)

The research setting is, in fact, constituted from the activities and procedures of members of the setting, including those of the researcher (Garfinkel 1984). For that reason, the terms 'activity' and 'setting' may be treated as interchangeable in what follows. There are two forms of the unique adequacy requirement, a weak 
one and a strong one. The weak requirement demands that the researcher acquires a working competence in the activities and procedures described, thus coming to a shared understanding with others engaged in those activities.

Thus, to analyse site activities adequately, we must know what any member engaged in those activities would ordinarily know. (NB. This does not mean that the researcher must know what every member of the setting knows, nor everything that any member knows. The test is competence in performing the activity described.) The weak requirement is proposed as a criterion for adequate ethnography (Garfinkel \& Wieder 1992). Thus, the ethnographer can produce an adequate account only to the extent that s/he appreciates the understanding of the setting which any other member of that setting would have. The question of whether that understanding has been achieved is a matter for the judgement of any other competent practitioner.

The strong form of the requirement demands that the methods of analysis used to describe an activity should be derived directly from that activity. This criterion rests on the assumption that the methods of analysis that practitioners use are sufficient to the purpose of producing a description of their practice and the decision that the introduction of additional analytic methods must involve some distortion of the description produced. If we accept that members understand their own activities and that these activities are constitutive of the settings in which they are carried out, then additional analysis is unnecessary for the production of an adequate description. (NB. The strong requirement thus 
excludes from the resulting ethnographic account any judgements as to the effectiveness or efficiency of participants practices that do not originate from the practitioners themselves.)

\section{(ii) The production of general observations}

As Herbert points out, “ethnographers typically focus on a single or very small number of cases" (ibid. p560) and suggests four ways in which the problem of generalizing from such a sample may be overcome. Thus, a setting may be chosen that can "plausibly stand in for other cases" (ibid.). Two cases may be compared in order to isolate motivations which account for similarities and differences between them. Third, ethnography may be used to explore the reasons for puzzling quantitative findings. Finally, ethnographic studies may be used as a means of testing theoretical predictions.

A combination of the first two strategies are adopted here: the observations below are regarded as likely to be typical of other sites; this typicality is tested by comparison with the previous studies discussed above. It is confirmed by the findings, which reveal considerable agreement with those of earlier studies.

As any construction manager will affirm, every project is different. The project from which this report emerges was more different than most. This has set 
particular limits on the general conclusions that may be drawn. Nevertheless, the closeness of observation permitted in this case may have enabled other conclusions which would not otherwise have been possible. The report covers 14 weeks participant observation on an experimental construction site, the European In-Situ Concrete Building Project at BRE’s Cardington laboratory, involving the erection of a seven story concrete frame.

The concrete frame was built on top of a previously prepared concrete slab within the BRE laboratory, a large hanger originally designed to house air-ships. Thus the site was protected from most of the effects of inclement weather and was singularly free of mud. The experimental setting provided the site organisation with unusual problems and made necessary unusual ways of working: work was subject to the demands of various research tasks, operatives having to work around various measuring instruments and co-ordinate their activities with those of researchers. In addition, the slab falsework system was changed every two floors, in order to allow study of different systems. These technical considerations will have affected the levels of risk and consequent incidence of accidental occurrence on site, but will not have had significant direct consequences for the patterns of authority or processes of learning discussed here.

The character of the project as a simulation involved a pretence on the part of those involved that the building under construction was situated on a busy high street. Such a 'double setting' (Francis 1989) can complicate the understanding of motivation, it is important to note therefore, that the observations reported 
below are restricted to describing reactions to real and not simulated problems.

More significantly, the contractual context was very different to that under which the contractor usually works: the project was 'non-commercial', there was no formal contract and no main contractor standing between the sub-contractor and the client. It is possible that these conditions had an ameliorating effect on the power struggles and tensions normally found in the industry. It is certainly the case that the project was not among the more confrontational that occur. Nonetheless, as the report below shows, there was ample evidence of contested authority.

There was also an unusually low degree of specialization on the project, due to the client's requirement that as far as possible operatives should remain on the job throughout the whole project. Thus, the contractor had selected operatives who were multi-skilled and flexible, to avoid the need for bringing specialists onto the site for short periods of time. This too may have had beneficial effects on the quality of relations on site, reducing organisational complexity and the consequent risk of conflict.

(iii) Representation and reflexivity

In contrast to the two previously considered issues the concern with 
representational practices comes, as Herbert notes, from ethnographers themselves. Subsequent to the publication of Clifford \& Marcus' (1986) influential study, a concern with reflexivity on the part of researchers has become a widely valued quality. However, as Slack (2000) indicates, UA entails a rejection of this form of stipulative reflexivity. The insistence on reflexivity as a necessary professional practice in research violates the UA requirement by directing attention towards the practices of the researcher and away from the practices of the research subject.

(iv) Can unique adequacy constitute a critical perspective?

In a similar manner, UA requires that in doing research, the researcher does not set out with critical intention. However, this does not mean that the research report cannot be critical in its effect. This is because uniquely adequate research explicates the analytic perspectives of the subjects of the research and these can sometimes stand in critical relation to more widely accepted analyses originating from more powerful sources. Such is the case with the report of site management given below. Furthermore, we suggest that this site eye view provides a useful corrective to these dominant accounts. For, while uniquely adequate studies make no overall judgement as to the moral validity of competing versions, they do rest on the assumption that everyone is, as it were, an expert in their own life. Thus, accounts of construction site governance originating from the site itself are almost 
certain to bear a closer relation to the reality on the ground than those originating from elsewhere.

In this way the UA requirement represents a radically different approach to that usually adopted in critical studies. The latter normally relies upon a developed theory in order to sanction a grounded critical perspective; the former explicitly excludes the researcher from introducing a theoretical analysis, opting instead to ground the analysis empirically, in direct experience of the setting under study. Consequently, studies of organization which meet the UA requirement do not contribute to the development of theoretical generalisations. Instead they focus on organizational realities as they are experienced by the organization's members.

\section{Site knowledge and learning}

Findings reported in this section demonstrate how new knowledge was acquired on site through the method of trial and error. This is equally true of experienced operatives developing new methods of working and neophytes acquiring basic skills. With regard to the latter, it is shown in sub-section (i) how the learning of inexperienced operatives was supported by context specific instruction from more experienced members of the site community. In sub-section (ii) the risk inherent in developing new practices through this type of learning is highlighted. 


\section{(i) Learning: slinging a load}

In addition to the crane driver, there are two functions pertinent to the transportation of plant and materials around the site by use of the crane: banksman and slinger. The role of the slinger is to bundle and tie the items to be moved and attach them to the crane hooks. The banksman is charged with communicating with the crane driver, acting as his eyes on the ground. Within the first few days of arriving on site, the researcher was told that all banksmen and slingers were certified, that 'everybody is trained for everything'. After he had been on the project for some weeks, however, he was permitted by site personnel to perform the function of slinger. It will be argued here that this was not a consequence of laxness about safety on the part of personnel. Rather, it was a routine feature of a site culture which placed a high value on safety, but relied on informal, rather than formal controls.

How then do operatives learn? Discussion with operatives revealed that, notwithstanding efforts to provide formal training, they had received their real training on the job: they learn by watching more experienced operatives; they learn by trying things out; or they learn by direct instruction. The experience of the researcher himself illustrates the use of these three modes in a logical sequence. In acquiring the ability to sling loads he first observed the activity, then attempted to help, by attaching one of the crane hooks. He was told, "no, do 
it this way" (with the open end of the hook facing outwards). On occasions where operatives were seen to be learning from direct instruction, it was tied to their activities in this way. Thus, for instance, two younger operatives who had begun to strike the formwork at the edge of a slab were told by a more experienced operative to wear safety harnesses.

More common was to observe operatives learning by trying things out. This type of learning took place at all levels of experience. Thus, on one hand, two operatives were seen to spend a morning attempting to dismantle some of the slab formwork from above, without going beyond the handrailing at the edge of the slab. Their ineffectual efforts contrasted sharply with those of a more experienced operative, who used a safety harness and went beyond the edge of the slab onto the falsework itself. On the other hand, more experienced operatives were involved in developing new working methods by trial and error.

(ii) Developing new working methods: using a skip to pour concrete

As the most common method of learning was by trial and error, there was always an increased risk of injury at the bottom of the learning curve, whether it involved inexperienced young operatives, or skilled old hands learning new methods. Operatives were used to pouring slab concrete using a pump. However, for the Cardington experiment, it was required of them that they pour one slab using a 
skip.

When the skip was first used, it was done in a confused rush, with half a dozen people getting in each other's way. It is in these times of chaos when an accident sometimes seems likely to happen. The first time the concrete for a slab was poured with a skip, for instance, there was much confusion. Operatives were getting in each other's way and there seemed to be a danger of someone being caught by the skip, or tripping on the reinforcement and falling. There was a particular risk of tripping where the top reinforcement was sparse. For most of the area of the slab, operatives were able to walk across the rebars without paying particular attention to it. However, where reinforcement is sparse, a foot put down carelessly might easily be placed between the bars, rather than across them.

Normally, as the concrete is poured, it is mechanically vibrated (using a device known on site as a poker). The poker operator quickly learned not to vibrate the concrete as it was being poured, but wait until the skip and the operatives working around it had moved away. Operatives also learned how to exercise better control over the rate that the concrete was poured out of a skip. This meant that it could be spread more evenly and at a rate that was manageable for those who were spreading it with shovels. Achieving a steady flow of concrete and consequently a more even spread, resulted in a more efficient distribution of the concrete, as well as a more controlled and safer operation. Although the total pouring time came down from about 80 seconds per skip to under 30 seconds, the operation on these later pours looked a lot less hurried. 


\section{Site organisation, status and authority}

In this section we describe a pattern of hierarchy and informal authority which was posited on membership of skill groups, experience on site and demonstrated ability. In particular, we highlight the role of the elite 'tricky men' and its implications for both site management and their own safety practice. However, the interplay of craft membership on the one hand and practical ability on the other, together with the sometimes competing demands of family loyalty, constituted an organisational structure of the site which was complex and sometimes ambiguous.

The core of the contractor's labour force, the formwork carpenters, or 'chippies', can also be regarded as the core of a work culture which values practical and experiential knowledge and devalues academic and professional knowledge. There is a tendency for the chippies to consider themselves to have a higher status than the other operatives on site, as they 'have a trade'. They were at the 'front line' in the erection of the structure, the most exposed to risk; the general foreman was himself a chippy. There can be said to be two types of chippy. Those that the Project manager referred to as 'tricky men', capable of performing the more difficult jobs which needed doing from time to time; and those who are predictable, reliable and of average competence. 
Overall responsibility for the site rested with the contractor's site agent, or project manager. However much of the day to day management, including ongoing labour allocation and development of detailed working methods, was carried out by the general foreman and his tricky men. For instance, when I asked the project manager whether he had worked out a novel piece of falsework, he referred me to one of the tricky men. As he observed, on another occasion,

“You can’t tell men like [the tricky men] what to do. Sometimes, they’ll come up to me and say, 'we could do it like this' and I'll say, 'Yeh'.”

The tricky men themselves expressed resentment on a number of occasions, of others, senior in the contractor's organization, but not directly charged with managing their activities, who attempted to tell them what to do.

The control that the tricky men exercised over their own work had important implications for the safe execution of that work. As is usual in the industry, site employees worked long hours. The informal nature of arrangements on site made it possible for operatives to control the risks associated with fatigue. Thus, for instance, the tricky men were observed striking formwork at the edge of the building. This involved working for an extended period of time in an exposed position. The tricky men worked very quickly for a period of about three hours. As the project manager commented: “they wouldn’t be able to keep up that pace all day; this afternoon they'll do some more mundane work”. 
While the tricky men had no formal authority on site, they commanded respect for their ability and were often consulted for advice by other operatives. In addition, they were able to exert considerable pressure on those whom they considered to be acting in an unacceptable manner. This took the form of a cutting humour, which had considerable impact on those who became its target. One operative's decision to leave the site appeared to have been influenced by constant comments to the effect that he was not 'pulling his weight'.

A second distinct group of operatives were the steelfixers. Employed by a separate company which sub-contracted to the frame contractor, the steelfixers had an ambiguous status vis-a-vis the chippies. Although, in the view of the chippies, steelfixing "is not considered a trade," as the foreman put it, this was disputed by the steelfixers themselves. In characterizing steelfixers, it was normal for others to stress the physical strength of these operatives, derived from lifting and placing steel reinforcement bars (known as rebars) and tying them together with wire. However, a steelfixer must also be able to read complex engineering drawings and to work in a systematic manner to place the bars correctly. This approach carried over into other activities the steelfixers undertook. Thus, when they dismantled the falsework, they did this in a more systematic manner than other workers. Steelfixers are also more averse to safety risks than the chippies; their usual work brings them into less exposure to risk.

In addition to these two major groups, there were two other individuals who practised a specialisation during the course of the project. One member of this 
group specialised in vibrating the concrete. This involved using a motorised device known as a 'poker' which was inserted into the concrete in order to compact the concrete as it was poured. He was also given responsibility for maintaining guardrails, a job that would be given to an experienced scaffolder on a larger site. The researcher was told that on a large commercial site, erecting and striking falsework would involve further specialisations, which were not visible at Cardington.

The crane driver worked for a separate sub-contractor, who would normally have a contract with the frame contractor. At Cardington, this company was contracted directly to the employer. The crane driver is a man apart from the rest of the site. Isolated in his cab, he must be constantly aware of activities on the ground and able to co-operate closely with other operatives, at the same time as being cut off from most of the lively social life of the site.

In addition to these occupational relations, matters were complicated further by family ties. Among the twenty or so personnel who were on site at one time or another, there were two father/son relationships, one father-in-law/son-in-law and one sibling relationship. Members of the same family tended to be confined to the same occupational grouping, but these relationships could nevertheless cut across expected lines of authority. 


\section{Knowledge, authority and conflict}

In this section, we examine a further reason for the complexity and ambiguity of authority relations on site, the interweaving of formal and informal patterns of status and authority. An example is given of how the experiential knowledge base underpinning site authority came into direct competition with professional engineering knowledge. The ensuing conflict significantly delayed the implementation of a safety measure that was felt to be necessary by the planning supervisor, but disputed by the tricky men.

The examples given in section 4 illustrate the highly informal nature of the process by which operatives acquire their skills. Indeed, for the tricky men, this informality was a point of pride. Their attitude to formal training was dismissive: “They come down to site and look for someone who isn’t doing anything. Then they take him away and give him some training. We're always too busy.” This attitude contrast sharply with that usually found among engineers whose expertise is based on possession of a body of classroom taught knowledge.

Furthermore, creativity in overcoming the contingencies of work on site is both satisfying to operatives and necessary to the smooth progress of construction, but could lead to conflict with engineers. For instance, the construction and use of a makeshift loading platform, built by operatives with no recourse to a formal design, provoked questions, initially from the planning supervisor and then from other engineers connected with the project as to the stability of the design. Under 
pressure from the site meeting, the platform was first given extra support. Later, a second smaller platform was designed by one of the contractor's engineers.

However, operatives were reluctant to implement these measures and continued to maintain that the original platform was perfectly safe.

In the context of the complex relations prevailing on site, it was difficult for nonsite personnel to impose their authority. This was a particular problem for the planning supervisor, who attempted on several occasions to have measures taken on site which he perceived to be in the interests of improved safety. These attempts to initiate action on site were continually frustrated. If he made a direct approach to operatives, he was told they needed the authority of their own management in order to act. However, requests made to the contractor's project manager would often not be implemented, due to the looseness of his own control over site activities.

\section{Discussion}

These findings confirm insights from previous ethnographic studies pertaining to knowledge and authority on site. In so doing, they constitute confirmatory evidence for the typicality of these previous studies and of the setting examined here. 
New findings pertaining to knowledge and learning processes include: details of how new knowledge is acquired through trial and error; details of how knowledge is disseminated in the community of practice through instructed practice; and an insight into the ways in which competing bodies of knowledge underpin competing authority structures. New findings pertaining to relations of authority include: details of the role of elite manual workers and the informal authority they hold; details of the complexity of informal relationships of authority; insight into the ambiguous and often ineffective nature of formal authority relations. With the possible partial exception of the last point, it is difficult to see how any of these findings could be argued to have been a product of the unusual conditions of the setting. It is conceivably possible that the relaxation of usual contractual controls allowed site personnel an increased scope for confounding the efforts of the planning supervisor, but this seems to us unlikely. The 'playing for time' nature of the contest, suggests a strategy of the subordinate. At the same time, the presence of commercial constraints would simply have increased the incentive on site personnel to resist time consuming safety measures.

It has been shown how competing conceptions of knowledge and authority operate at site level to impede attempts at improving safety performance. The experiential knowledge which is valued by site personnel forms a basis for the recognition of authority on site which can bring site personnel into conflict with engineers, whose scientifically based, classroom taught knowledge sometimes stands in contradiction to it. 
On the other hand, it has also been demonstrated that this knowledge and authority is itself a basis for safe practice on site, both in enabling knowledge to be disseminated through appropriate and timely instruction and in allowing operatives in risk exposed situations to control the pace of their own work.

\section{Conclusions}

The unique adequacy requirement restrains us from attempting any objective evaluation of the relative merit of these competing perspectives. From the point of view of UA studies, this is a practical matter for construction organisation personnel to resolve. The significant point to note from this perspective is that engineers will continue to stand by the scientific credentials of their own knowledge, while site operatives will be equally firm in trusting to their own hard won experience.

From the point of view of health and safety management, the critical point is that the forms of authority and knowledge discussed here can inhibit the dissemination of good safety practice:

- safety initiatives, however scientifically based, will meet significant resistance if they contradict the experiential knowledge of site operatives; 
- safety initiatives that do not make use of this experiential knowledge may fail to fully address hazards;

- methods of learning on site, particularly in the development of innovative practice are inherently hazardous.

From the health and safety perspective, there is a particularly urgent need for more research into this last aspect. However, the relationship between the competing bodies of knowledge and patterns of authority identified here presents a considerable challenge to organizational learning theory more generally, with consequences that go beyond health and safety to the broader question of how organizational innovation is achieved.

From the point of view of a critical perspective on situated learning theory, the lesson is drawn that there exists an alternative to shifting the focus from participant observation to historical study, or theorising about social structure. It has been demonstrated here that ethnography carried out according to the UA requirement of methods is capable of revealing a fresh critical perspective on organizational reality and detailing the actuality of contested knowledge in practice.

The repeated concern in the literature with the absence of a proper analysis of power should be of no surprise to critical theorists. The tendency for power to be hidden is widely commented on in the literature. However, as Contu \& Willmott's 
(2003) own paper illustrates, such concerns can re-emerge in the course of a detailed ethnography. Ironically, it is not Orr's (1996) ethnographic monograph that neglects issues of power, but his shorter theoretical gloss on those findings (Orr 1990). On the other hand, it is apparent that continued theoretical injunctions to pay attention to 'power', 'structure', or 'macro-issues' have proved no guarantee against the disappearance of the phenomenon in research reports. We therefore suggest that the UA requirement of methods should be considered as a possible and perhaps necessary corrective to the dangers of reporting bias.

Finally, in demonstrating that these issues of contested knowledge, contested authority and organisational conflict are treatable outside of a theoretical or historical framework, we propose an extension to the original insights of situated learning theory. Crucially, this approach has successfully collapsed several key distinctions in traditional learning theory, including: the active teacher vis a vis the passive student; knowledgeable individuals vis a vis contingent organizations; and learning processes vis a vis bodies of knowledge. Knowing is revealed in specific detail as an active social process inextricably situated in the social settings it inhabits. We suggest that the current study reveals the possibility of a similar perspective on power. Actual on site outcomes arise and are indivisible from particular contested relations of authority, which are in turn intrinsically related to particular issues of contested knowledge. As Sharrock and Watson (1988) have observed, if we do not make a theoretical distinction between action and structure, we will be relieved of the theoretical task of later reconciling them. 
We thank the UK Health and Safety Executive, who funded the research reported here. Research Project: RSU Ref. 3433/R33.034

\section{References}

Appelbaum, H. A. (1982) 'Construction Management; Traditional versus Bureaucratic Methods', Anthropological Quarterly, 55(4): 224-234.

Blackler, F. (1995) 'Knowledge, knowledge work and organization: an overview and interpretation', in Organization Studies, 16(6)1021-1046.

Clarke, L. \& Wall, C. (1998) A Blueprint for Change; Construction Skills Training in Britain, The Policy Press, Bristol.

Contu, A. \& Willmott, H. (2003) 'Re-embedding situatedness: the importance of power relations in learning theory,' in Organization Science, 14(3):283-296.

Engeström, Y. (1987) Learning by Expanding: An Activity Theoretical Approach to Developmental Research, Orienta-Konsultit, Helsinki. http://lchc.ucsd.edu/MCA/Paper/Engestrom/expanding/toc.htm 
Engeström, Y. (2004) 'New forms of learning in co-configuration work,' paper presented at ICTs in the Contemporary World: Work, Management and Culture, Department of Information Systems Seminar, LSE, 22 ${ }^{\text {nd }}$ January.

Francis, D. (1989) ‘Game Identities and Activities: Some Ethnomethodological Observations’, in D. Crookall \& D. Saunders (eds.) Communication and Simulation: From Two Fields to One Theme, Multilingual Matters.

Garfinkel, H. (1984) Studies in Ethnomethodology, Polity Press, Cambridge.

Garfinkel, H. (2002) Ethnomethodology’s Program: Working out Durkheim's Aphorism, Rowman \& Littleford, Lanham.

Garfinkel, H., Lynch, M. \& Livingston, E. (1981) 'The Work of a Discovering Science Construed with Materials from the Optically Discovered Pulsar', in Philosophy of the Social Sciences, 11:131-158.

Garfinkel, H. \& Wieder, D. L. (1992) 'Two Incommensurable, Asymmetrically Alternate Technologies of Social Analysis', in G. Watson \& R. M. Seiler (eds.), Text in Context, Sage, London, pp. 175-206.

Gherardi, S. \& Nicolini, D. (2002) 'Learning the Trade; A Culture of Safety in Practice' in Organization, 9(2):191-223. 
Harvey, R. C. \& Ashworth, A. (1997) The construction industry of Great Britain (second edition) Butterworth Heinemann, Oxford.

Herbert, S. (2000) 'For ethnography', in Progress in Human Geography 24(4):550-568.

Lave, J. (1993) 'The practice of learning,' in Understanding Practice:

Perspectives on activity and context, in S. Chaiklin \& J. Lave (eds.) Cambridge University Press.

Lave, J. \& Wenger, E. (1991) Situated learning: legitimate peripheral participation, Cambridge University Press.

Morton, R. (2002) Construction UK; Introduction to the Industry, Blackwell, Oxford.

Myers, K. (2003) Health and Safety Performance in the Construction Industry; Progress since the 2001 Summit, Health and Safety Executive.

Orr, J. E. (1990) 'Sharing knowledge, celebrating identity: community memory in a service culture,' in D. S. Middleton \& D. Edwards (eds.) Collective Remembering, Sage, London.

Orr, J. E. (1996) Talking About Machines: An Ethnography of a Modern Job, ILR 
Press, New York.

Rooke, J. \& Seymour, D. (2002) 'Ethnography in the construction industry: Competing bodies of knowledge in civil engineering,' in R. Fellows and D. Seymour (eds.) Perspectives on Culture in Construction, CIB, Rotterdam.

Rooke, J., Seymour, D. \& Fellows, R. (2004) 'Planning for Claims; An Ethnography of Industry Culture', in Construction Management and Economics, 22:655-662.

Seymour, D. \& Hill, C. (1995) 'The Firstline Supervisor in Construction: A Key to Change?' in ARCOM 95, Proceedings of the Eleventh Annual Conference of the Association of Researchers in Construction Management, Loughborough University.

Sharrock, W. W. \& Watosn, R. (1988) 'Autonomy among social theories: the incarnation of social structures,' in N.G.Fielding (ed.) Action and Structure, Sage, London.

Slack, R. (2000) 'Reflexivity or Sociological Practice: A Reply to May' Sociological Research Online, 5(1)

<http://www.socresonline.org.uk/5/1/slack.html>

Whittington, C., Livingston, A. \& Lucas, D. A. (1992) Research into 
Management, Organisational and Human Factors in the Construction Industry, HSE Contract Research Report No. 45/1992, HMSO. 